\title{
The effect of endoscopic sinus surgery on quality of life and absenteeism in patients with chronic rhinosinuitis - a multi-centre study*
}

\author{
Pernilla Sahlstrand-Johnson' ${ }^{1}$, Claire Hopkins², Bodil Ohlsson³, \\ Marianne Ahlner-Elmqvist ${ }^{4}$
}

Rhinology 55: 251-261, 2017

https://doi.org/10.4193/Rhino16.126

*Received for publication:

April 7, 2016

Accepted: March 10, 2017
1 Department of Oto-Rhino-Laryngology, Head and Neck Surgery, Lund University, Skåne University Hospital, Malmö, Sweden

2 Department of Otolaryngology Guy's and St Thomas'Hospital, London, United Kingdom

${ }^{3}$ Lund University, Skåne University Hospital, Division of Internal Medicine, Malmö, Sweden

${ }^{4}$ Department of Health Sciences, Faculty of Medicine, Lund University, Lund, Sweden

\begin{abstract}
Background: Chronic rhinosinusitis with and without nasal polyps (CRSw/sNP) are common conditions decreasing health-related quality of life (HRQOL). Individual symptoms capable of predicting outcome after endoscopic sinus surgery (ESS) are poorly defined, and the indirect costs of CRS is rarely reported in Europe.
\end{abstract}

Methodology: Patients with CRSw/sNP admitted for ESS were prospectively enrolled. Patients completed the 22 Sinonasal Outcome Test (SNOT-22), the short-form 36-item questionnaire (SF-36), a Visual Analogue Scale (VAS) and reported CRS-related absenteeism pre- and post-operatively.

Results: 181 patients were included. The SNOT-22 score diminished from 51.8 (48.7-55.0) pre-operatively to 33.0 (29.2-36.8) at 6 months. 64\% achieved a clinically important improvement in the SNOT-22. SF-36 scores improved statistically significantly in all domains except "Role Emotional". The VAS score halved from 68 (65-71) to 34 (29-39) at 6 months post-operatively. A pre-operative SNOT-22 score $>20$ implied a greater chance of score improvement after 6 months. A multivariate model identified individual items associated with SNOT-22. Further, patients that had $<12$ months of sinus disease derived greatest benefit. CRS-related absenteeism dropped from 8-14 days to 1-7 days 12 months after ESS.

Conclusions: This prospective study showed that ESS significantly improved the HRQOL and decreased absenteeism of patients with CRSw/sNP. Shorter duration of disease and "Need to blow nose" and "Blockage/congestion of nose" of SNOT-22 were identified as predictive factors for good surgical outcome.

Key words: absenteeism, chronic rhinosinusitis, nasal polyps, outcome, quality of life, sinus surgery

\section{Introduction}

Rhinosinusitis is an inflammatory process involving the mucosa of the nose and one or more of the paranasal sinuses ${ }^{(1)}$. Diagnosis is made on the basis of a symptomatic definition, with supporting findings on clinical examination and CT imaging. Nasal polyps (NP) are tumour-like hyperplastic swellings of the nasal mucosa, most commonly originating from within the ostiomeatal complex. Chronic rhinosinusitis (CRS) can occur with (CRSwNP) and without NP (CRSsNP).
The prevalence of CRS in Europe is estimated to approximately $9 \%{ }^{(2,3)}$, while the prevalence of CRSwNP is estimated to about $2.7 \%-4 \%{ }^{(3,4)}$. Thus, CRS can be considered a significant health problem, which has been found to have a detrimental effect on health-related quality of life (HRQOL). We have previously reported that Swedish patients with CRS, with and without NP, referred for endoscopic sinus surgery (ESS) have significantly impaired HRQOL ${ }^{(5)}$. We found differences in $\mathrm{HRQOL}$ scoring in the 22 item Sinonasal Outcome Test (SNOT-22) between patients 
with and without NP, with respect to loss of sense of taste/smell, cough, and facial pain and pressure.

The study of Deal and Kountakis ${ }^{(6)}$ showed that patients with NP have worse HRQOL compared to CRS patients, while the study of Hopkins et al. ${ }^{(7)}$ found significant differences in prevalence of anosmia and facial pain between phenotypes, although total SNOT-22 scores were slightly lower in CRSwNP patients undergoing surgery compared with CRSsNP. However, both studies confirmed that the improvement in HRQOL after surgery was more pronounced in patients with CRSwNP compared to CRSsNP. Additionally, both Ragab et al. ${ }^{(8)}$ and Alobid et al. ${ }^{\left({ }^{9}\right)}$ have found that general HRQOL improved significantly with both medical and surgical treatment in patients with CRSwNP. In agreement with others ${ }^{(4,10-15)}$, Dietz de Loos et al. ${ }^{(16)}$ found a higher portion of asthmatics in the CRSwNP group compared to the CRSsNP and also identified six items within 31-item outcome measure (RSOM-31) predictive for the presence of nasal polyps in a multivariable model. Recently published data suggests that the improvement in HRQOL occurring after ESS may differ depending on the duration of CRS prior to surgery ${ }^{(17,18)}$. However, there is sparse published analysis of items within the SNOT-22 in terms of predicting improvement after ESS. Deconde et al.

(19) have described that the decision to elect ESS over continued medical management was found to be predicted more by the general HRQOL domains of SNOT-22, surrounding sleep and psychological dysfunction.

In spite of the fact that CRS is considered to be a common condition, there is very little published data regarding the impact of CRS on the health economy, in particular in Europe. A study evaluating the effectiveness of a heamopoietic agent (filgrastim) found no benefit over placebo, but showed the costs of CRS to be $896 €$ and associated absenteeism was 9 days during a 24-week interval ${ }^{(20)}$. Rudmik et al. ${ }^{(21)}$ have reported a reduction of preoperative productivity costs in the United States (US) after ESS from $\$ 9,190$ to $\$ 3,373$.

The primary aim of this prospectively conducted study was to assess the improvement in HRQOL after ESS. Secondary aims were: 1) to analyse whether certain sinonasal symptoms in SNOT-22 can be used to predict a good postoperative outcome measured by HRQOL; 2 ) to investigate whether the influence of the disease duration had an effect on the outcome of surgery in patients treated in a different healthcare environment; and 3) to assess whether absenteeism decrease after ESS.

\section{Materials and methods}

Study population

Patients aged $\geq 18$ years with a diagnosis of CRSwNP or CRSsNP referred for ESS at 10 hospitals (five university and five regional hospitals) in Sweden during 2008-2009 were prospectively enrolled. The diagnostic criterion for CRSs/wNP was defined as the presence of two or more symptoms, one of which should

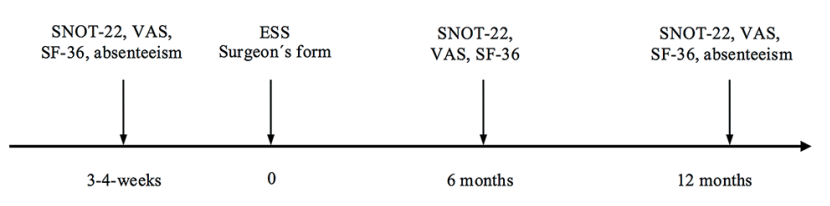

Figure 1. Flowchart of the study including the questionnaires that the population answered. SNOT-22 $=22$ Sinonasal Outcome Test; VAS = visual analogue scale; SF-36 = 36-item short-form questionnaire; ESS = endoscopic sinus surgery.

be nasal congestion/obstruction/blockage or nasal discharge (anterior/posterior nasal drip), and/or facial pain/pressure, and/ or reduction or loss of smell for more than 12 weeks. Additionally, there should be endoscopic signs and/or radiological signs of CRS with or without nasal polyps on computed tomography (CT), according to European Position Paper on Rhinosinusitis and Nasal Polyps (EP3OS) ${ }^{(1)}$. CRSwNP were defined as bilateral, endoscopically visualized in middle meatus, and CRSsNP as no visible polyps in middle meatus, if necessary following decongestant ${ }^{(1)}$. Exclusion criteria were pregnancy, gross immunodeficiency, congenital mucociliary problems, cystic fibrosis, systemic vasculitis, and granulomatous diseases, as these conditions may induce sinus disease and affect HRQOL. The ability to understand the Swedish language was mandatory for inclusion.

\section{Study design}

For study design, see Figure 1. The patients were examined at the hospital by sinus surgeons, who diagnosed the patients with CRSwNP or CRSsNP, and referred the patients for surgery. All patients had previously received adequate medical treatment according to EP3OS guidelines (1) without satisfactory response, before being referred for surgery; i.e., the patients with CRSSNP had received nasal steroid and nasal lavage for at least 3 months, and patients with CRSwNP had received nasal steroids for at least 3 months and one or more courses of oral steroids. At surgery, the surgeon stated the extent of sinus surgery that was performed. The postoperative care was recorded, including if the patients received nasal packing at surgery, but no interference was made in the clinical postoperative routine at each hospital.

The patients included in the study were sent questionnaires (see below) 2-4 weeks preoperatively, together with information on their appointment for surgery. Two HRQOL questionnaires and one VAS scale were used, as reported previously ${ }^{(5)}$. All patients completed a demographic form and were asked how many days they thought they had been absent from work (absenteeism) due to sinus problems during the past 12 months using the following categories: 0 days, 1-7 days, 8-14 days, 15-30 days or $>30$ days. A clinician-reported data form was completed by the surgeons at the time of surgery. At 6 and 12 months after sur- 
gery, the patients were sent the same questionnaires again. All the questionnaires were returned to the study coordinator, and the data was recorded anonymously in a computer database.

The study was performed according to the Helsinki convention. The Regional Ethics Review Board at Lund University approved the study protocol. The patients gave their written, informed consent to participate and were informed that participation in the survey was voluntarily, and would not mean any change in care or surgery procedure.

\section{Questionnaires}

\section{Sinonasal Outcome Test (SNOT-22)}

SNOT-22 was used to assess HRQOL and symptoms associated with rhinosinusitis. It contains 22 nose-, sinus-, and general items and is a modification of SNOT-20 developed by Piccirillo ${ }^{(22)}$ and Hopkins ${ }^{(23)}$. This questionnaire is one of the most used sinonasal outcome measure today, which has been validated and found to be easy to use ${ }^{(22)}$. It is also available in numerous languages ${ }^{(5,21,25-28)}$. The theoretical range of the total score is $0-110$, with lower scores implying a better HRQOL. The minimally important difference when using the questionnaire is 8.9 (24), i.e., a change of less than 9 points cannot be perceived as a real improvement or impairment by the patient.

Four domains within the SNOT-22 have been described, which help clinical interpretation of the questionnaire (29); two constructs address disease-specific symptoms (rhinologic and ear/ facial i.e., SNOT-22 items number 1, 2, 3, 4, 5, 7, 8 and 6, 9, 10, 11 and 12 respectively) and two address more global aspects of HRQOL (sleep function and psychological issues, i.e., SNOT-22 items 13, 14, 15, 16 and 17, 18, 19, 20, 21 and 22, respectively).

\section{6-item short-form questionnaire (SF-36)}

SF-36 is an extensively used HRQOL instrument, which provides reproducible, reliable data on large populations, and has been shown to be useful as a global health monitor in clinical practice. It is available in Swedish ${ }^{(30)}$ and reference data are available for many different conditions. The SF-36 questionnaire is divided into eight subscales of general health and ordered according to the degree to which they measure physical vs. mental health. These subscales are physical functioning (PF), role functioningphysical (RP), bodily pain (BP), general health (GH), vitality (VT), social functioning (SF), role functioning-emotional (RE), and mental health (MH). Two additional dimensions can be calculated, namely physical (PCS) and emotional health (MCS), based on weighting of the importance of the eight subscales. The raw data are recoded when analysed; high scores imply a better $\mathrm{HRQOL}$ and the maximum score is 100 .

\section{Visual analogue scale (VAS)}

The VAS is a psychometric response scale usually represented by a horizontal line, $10 \mathrm{~cm}$ in length, anchored by word descriptors at each end. The patient indicates the position on the line that they feel represents their perception of their current state, in response to the question "How troublesome are your symptoms of rhinosinusitis?". Lim et al. ${ }^{(31)}$ have considered the relationship between subjective assessment instruments in CRS and found that 'mild' equates to a VAS of $\leq 3$, 'moderate' to a VAS of 4-7 and 'severe' to a VAS of $>7$. The correlation between VAS- and HRQOL-scoring has previously been described ${ }^{(5)}$.

\section{Duration groups}

To be able to analyse the impact of duration of sinonasal disease on the surgical outcome, the population was categorized into three groups based on the number of months they had had their symptoms: $<12$ months, 12-60 months, and >60 months, according to previous analysis by Hopkins et al. ${ }^{(32)}$.

\section{Statistical analysis}

Simple mean imputation was used for missing data, when at least $50 \%$ of the items had been completed. This means that the mean of the values of the completed item is used as the value of the missing data. This method has been proven to be best for HRQOL instruments that use unweighted sum scores ${ }^{(33)}$. For SF36 , it was required that $50 \%$ of the items in the same subscale had to be competed for simple mean imputation to be used. Percentages of change in SNOT-22 scores were calculated for each patient using the formula [(pre-operative score - postoperative score)/pre-operative score $x$ 100] before calculating population means. A larger percentage change reflects a greater benefit.

Linear regression analysis was performed to identify potential significant predictors among baseline demographic factors, VAS scores and SNOT-22 scores with an improvement in the SNOT-22 sum. The baseline SNOT-22 scores were dichotomized based on a symptom score $\geq 2$ (i.e. "mild or slight problem" and worse) ${ }^{(16)}$. To begin with, all the dichotomized variables were assessed against improvement in univariable linear regression analyses. Thereafter backward multiple linear regression analysis was performed to identify a model with significant predictors among baseline SNOT-22 scores with an improvement in the SNOT-22 sum.

Univariable linear regression analyses were used to analyse the relationship between baseline SNOT-22 scores with an improvement in the SNOT-22 sum within the four domains; rhinological symptoms, sleep function, ear/facial symptoms and psychological function ${ }^{(29)}$.

Preoperative SNOT-22 scores were categorised into 9 groups based on 10-point increments beginning with 0 and ending with 110. Since the number of patients in the first and last group were too small (one and zero patient, respectively) they were combined with the nearby groups (0-20 and 91-110 group, 
Table 1. Characteristics of the study population.

\begin{tabular}{|c|c|c|c|}
\hline & $\begin{array}{l}\text { Chronic rhinosinusitis with nasal } \\
\text { polyps } n(\%)=113(62)\end{array}$ & $\begin{array}{l}\text { Chronic rhinosinusitis without } \\
\text { nasal polyps } n(\%)=68(38)\end{array}$ & Total population $\mathrm{N}=181$ \\
\hline Male & $80(71)$ & $24(35)$ & $104(57)$ \\
\hline Female & $33(29)$ & $44(65)$ & $77(43)$ \\
\hline $\begin{array}{l}\text { Previous functional endoscopic } \\
\text { sinus surgery* }\end{array}$ & $36(34)$ & $8(13)$ & $44(26)$ \\
\hline Allergic rhinitis\# & $34(30)$ & $12(18)$ & $46(26)$ \\
\hline Asthma\# & $38(34)$ & $6(9)$ & $44(24)$ \\
\hline Acetyl salicylic acid intolerance\# & $16(14)$ & $6(9)$ & $22(12)$ \\
\hline
\end{tabular}

*) surgeon-reported; \#) self-reported. N/n (\%) = number (\%) of patients.

respectively). The proportion of patients achieving a minimal clinical important difference (MCID) of at least a 9-point improvement on the SNOT-22 group was calculated. The percentage of relative improvement for each preoperative SNOT-22 group was also calculated using the formula: [(mean postoperative score - mean preoperative score)/mean preoperative score $\times 100]$. Larger negative percentages of relative improvement indicate larger postoperative improvements compared to the patient's preoperative SNOT-22 score.

The Kruskal-Wallis test and the Mann-Whitney U-test were used to compare the QOL data between groups. Fisher's exact test was used to compare absenteeism between groups. $P$ values below 0.05 were considered as statistically significant. Data are presented as means with $95 \%$ confidence interval $(\mathrm{Cl})$ or standard deviation (SD).

All analyses were conducted using IBM SPSS Statistics 22 for Windows (IBM Corporation, Armonk, NY, USA).

\section{Results}

In all, 181 patients were included in the study at the time of undergoing ESS. There was a progressive loss to follow-up, with 122 patients returning questionnaires at 6 months (67.4\%), and 107 patients at 12 months (59.1\%). The causes of the drop out were failure to return the forms (despite reminders) and difficulties in locating the patients who moved from the original address. There were no difference in the preoperative scoring between those patients who responded postoperatively and those who failed to return postoperative profomas (data not shown). Of the 181 included patients, 113 were diagnosed with NP and 68 without NP. Some of the demographic data are described in Table 1. There was a statistical difference in gender ( $p$ $<0.0001)$, asthma bronchialis $(p<0.0001)$ and previous surgery $(p=0.001)$ between patients with and without NP. In Table 2, the surgical procedures performed are described. Surgery of the uncinate process or maxillary sinus ostium was performed in
Table 2. Surgical procedures in percent (\%) performed in the study population.

\begin{tabular}{|lc|}
\hline Surgery & $\%$ \\
\hline Polypectomy & 47 \\
\hline Infundibulotomy & 84 \\
\hline Infundibulotomy and anterior ethmoidectomy & 62 \\
\hline Infundibulotomy and full ethmoidectomy surgery & 31 \\
\hline Infundibulotomy, full ethmoidectomy and frontal sinus & 25 \\
\hline $\begin{array}{l}\text { Infundibulotomy, full ethmoidectomy andsphenoidec- } \\
\text { tomy }\end{array}$ & 10 \\
\hline $\begin{array}{l}\text { Infundibulotomy, full ethmoidectomy, sphenoidectomy } \\
\text { and frontal sinus surgery }\end{array}$ & 19 \\
\hline
\end{tabular}

$84 \%$ of the patients. Septoplasty, to improve the surgical access, was performed in $13 \%$ of the cases.

\section{Changes in HRQOL after ESS SNOT-22}

The total SNOT-22 score decreased significantly from 51.8 (48.7-55.0) preoperatively to $33.0(29.2-36.8)$ at 6 months post-operatively $(p<0.0001)$, with maintained improvement 12 months after surgery (Table 3 ). There was no statistically significant post-operative difference in total SNOT-22 scoring between patients with and without NP. However, the patients with NP scored significantly higher in the question on "Loss of sense of taste/smell" ( $p<0.0001)$, but lower in the questions "Post-nasal discharge" ( $p=0.29)$, "Facial pain/pressure" $(p=0.037)$ and "Fatigue" $(\mathrm{p}=0.21)$ at 6 months postoperatively. The improvement in SNOT-22 scores across the cohort was clinically significant, with a mean improvement of more than double the MCID (8.9). An improvement of $\geq 8.9$ at an individual level was scored in $64 \%$ of the cohort. The improvement at 6 months in each of the four domains of SNOT-22 was 7.2 (5.7-8.6) (rhinologic), 3.3 (2.3-4.1) (ear/facial), 2.6 (1.6-3.5) (sleep) and 4.3 (2.8-5.5) (psychologic), $\mathrm{p}<0.0001$ for all domains. The patients without NP scored a bigger improvement than patients with NP in the ear/facial domain (5.3 vs. $2.0, p=0.001$ ). There was no significant difference 
Table 3. SF-36, SNOT-22 and VAS scores pre- and post-operatively.

\begin{tabular}{|c|c|c|c|}
\hline SF-36 & Preop Mean (95\% Cl) & 6 months postop Mean $(95 \% \mathrm{CI})$ & 12 months postop Mean $(95 \% \mathrm{Cl})$ \\
\hline \multicolumn{4}{|l|}{ Physical functioning } \\
\hline Total population & $80.8(77.9-83.6)$ & $87.2(84.1-90.3)^{*}$ & $85.7(82.1-89.3)$ \\
\hline CRSWNP & $82.8(79.4-86.2)$ & $86.8(82.8-90.8)$ & $83.7(78.8-88.6)$ \\
\hline CRSsNP & $76.9(71.8-81.9)$ & $87.0(81.0-92.9)$ & $88.0(82.5-93.4)$ \\
\hline \multicolumn{4}{|c|}{ Role functioning-physical } \\
\hline Total population & $63.5(57.9-69.2)$ & $73.4(67.2-79.7)^{*}$ & $72.2(64.8-79.6)$ \\
\hline CRSWNP & $67.2(60.5-74.2)$ & $73.0(64.7-81.3)$ & $69.0(59.0-79.1)$ \\
\hline CRSsNP & $56.5(46.4-66.6)$ & $73.4(63.2-83.6)$ & $75.0(63.4-86.6)$ \\
\hline \multicolumn{4}{|l|}{ Bodily pain } \\
\hline Total population & $63.9(59.7-68.0)$ & $71.9(67.4-76.4)^{*}$ & $70.7(65.6-75.9)$ \\
\hline CRSWNP & $71.0(66.0-76.1)$ & $72.6(66.5-78.7)$ & $71.6(64.5-78-7)$ \\
\hline CRSsNP & $50.4(44.1-56.8)$ & $68.4(61.0-75.8)$ & $68.4(60.4-76.3)$ \\
\hline \multicolumn{4}{|l|}{ General health } \\
\hline Total population & $60.6(57.4-63.8)$ & $64.8(60.9-68.6)^{*}$ & $64.4(59.6-69.3)$ \\
\hline CRSwNP & $62.3(58.5-66.2)$ & $66.3(66.4-71.3)$ & $63.7(57.4-70.0)$ \\
\hline CRSsNP & $57.4(51.7-63.1)$ & $61.8(54.9-68.6)$ & $63.8(55.2-72.3)$ \\
\hline \multicolumn{4}{|l|}{ Vitality } \\
\hline Total population & $51.4(47.9-55.0)$ & $60.6(56.8-64.4)^{*}$ & $61.5(55.9-66.1)$ \\
\hline CRSwNP & $54.6(50.3-58.8)$ & $63.2(58.5-68.0)$ & $62.7(57.0-68.4)$ \\
\hline CRSsNP & $45.5(39.3-51.8)$ & $54.3(47.2-61.3)$ & $57.0(48.7-65.4)$ \\
\hline \multicolumn{4}{|l|}{ Social functioning } \\
\hline Total population & $73.2(69.7-76.8)$ & $81.7(78.0-85.5)^{*}$ & $82.2(77.6-86.7)$ \\
\hline CRSwNP & $74.7(70.3-79.1)$ & $82.9(78.1-87.7)$ & $82.3(76.4-88.2)$ \\
\hline CRSsNP & $70.5(64.2-76.8)$ & $78.1(71.1-85.1)$ & $80.1(72.1-88.1)$ \\
\hline \multicolumn{4}{|l|}{ Role emotional } \\
\hline Total population & $71.0(65.4-76.5)$ & $74.1(67.8-80.4)$ & $74.7(67.7-81.7)$ \\
\hline CRSwNP & $72.0(65.0-78.9)$ & $74.7(66.8-82.7)$ & $73.6(64.3-83.0)$ \\
\hline CRSsNP & $69.1(59.5-78.2)$ & $72.9(62.2-83.6)$ & $73.9(62.1-85.6)$ \\
\hline \multicolumn{4}{|l|}{ Mental health } \\
\hline Total population & $73.2(70.5-75.9)$ & $77.8(74.6-80.9)^{*}$ & $77.6(74.0-81.2)$ \\
\hline CRSwNP & 74.7 (71.2-78.1) & $79.4(75.4-83.5)$ & $78.6(74.4-82.9)$ \\
\hline CRSsNP & $70.4(66.0-74.7)$ & $73.5(67.8-79.2)$ & $74.4(67.3-81.5)$ \\
\hline \multicolumn{4}{|l|}{ SNOT-22 } \\
\hline Total population & $51.8(48.7-55.0)$ & $33,0(29.2-36.8)^{*}$ & $32,6(28.4-36.8)$ \\
\hline CRSwNP & $49.4(45.3-53.4)$ & $33,6(27.8-39.5)^{*}$ & $30,7(24.9-36.4)$ \\
\hline CRSsNP & $56.0(51.1-61.0)$ & $35,2(29.3-41.2)^{*}$ & $38,6(30.9-46.2)$ \\
\hline \multicolumn{4}{|l|}{ VAS } \\
\hline Total population & $68(65-71)$ & $34(29-39)^{*}$ & $32(27-37)$ \\
\hline CRSwNP & 67 (63-72) & $34(27-40)^{*}$ & $34(27-40)$ \\
\hline CRSsNP & $69(63-74)$ & $36(28-44)^{*}$ & $29(20-37)$ \\
\hline
\end{tabular}

SF-36 = 36-item short-form questionnaire; SNOT-22 = 22 sinonasal outcome test; VAS = visual analogue scale; $95 \% \mathrm{Cl}=95 \%$ Confidence Interval of the Difference; CRSwNP = chronic rhinosinusitis with nasal polyps; CRSsNP $=$ chronic rhinosinusitis without nasal polyps; ${ }^{*}=p<0.05$ Kruskal-Wallis test and the Mann-Whitney U-test were used to compare groups. 


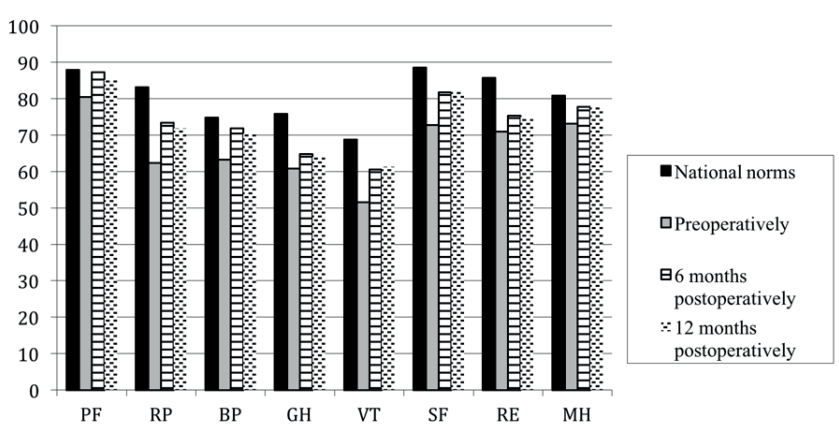

Figure 2. SF-36 health profiles for patients with chronic rhinosinusitis with and without nasal polyps and Swedish national norms. High score represent high level of functioning. $36=36$-item short-form questionnaire. Subscales of SF-36: Physical functioning (PF), role functioningphysical (RP), bodily pain (BP), general health (GH), vitality (VT), social functioning (SF), role functioning-emotional (RE), and mental health $(\mathrm{MH})$.

between these two patient groups in the other three domains (data not shown).

\section{SF-36}

Scores measured by SF-36 improved in all eight domains after surgery (Figure 2). At 6 months, all domains apart from the RE domain were improved compared to preoperatively ( $p<0.05$ ). After 12 months, this statistical significance decreased to non-significant differences in the RP and GH domains. Between 6 and 12 months, there was no significant change in SF-36 scoring, except for the PF domain $(p=0.012)$. There was no statistically significant difference in SF-36 scoring between the CRS patients with and without NP, except for in the MH domain 6 months after FESS, where the patients without NP scored worse $(p=0.035)$.

\section{VAS}

The total VAS score diminished from $68(65-71)$ to 34 (29-39) at 6 months after surgery, remaining at this level 12 months postoperatively (Table 3 ). The decrease of VAS score was strongly significant after 6 months $(p<0.0001)$, and did not change significantly 12 months post-operatively. There was no statistically significant difference between the CRSwNP and the CRSsNP in postoperative VAS scoring. Preoperatively, the majority of the cohort was classified as suffering from severe disease. This changed considerably postoperatively, leaving $60 \%$ with mild disease 12 months after surgery according to the VAS scoring (Figure 3 ).

\section{Prediction of outcome}

The preoperative SNOT score correlated significantly with an improvement in postoperative SNOT score. The SNOT score improvement increased with increasing preoperative SNOT-22 score. One point higher scores preoperatively meant an improvement

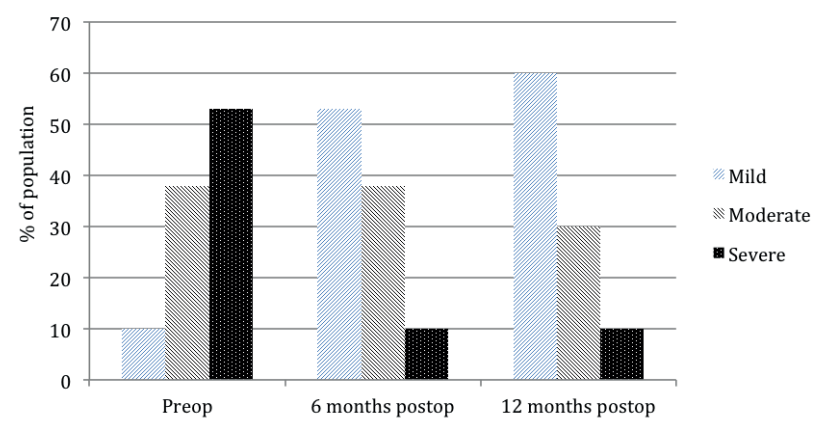

Figure 3. VAS groups in patients with chronic rhinosinusitis with or without nasal polyps. VAS = visual analogue scale; Mild disease $=$ VAS $\leq 3$; Moderate disease $=$ VAS 4-7; Severe disease $=$ VAS $>7$

of the postoperative SNOT score difference with 0.37 points ( $p$ $<0.0001$ ). Those patients with a score of $>20$ preoperatively had a $43 \%-83 \%$ chance of achieving the MCID 6 months postoperatively (Table 4).

Sixteen of the preoperative dichotomized SNOT-22 items were statistically associated $(p<0.05)$ with improvement in SNOT22 score according to the linear regression (Table 5). In the multivariate model scoring $\geq 2$ in "Lack of a good night's sleep" and "Frustrated/restless/irritable" remained as the most significant items associated with SNOT-22 improvement 6 months postoperatively. However, "Need to blow nose" and "Blockage/ congestion of nose" were the items with the highest coefficients suggesting them as most predictive items of SNOT-22.

Analysing the four subscales of SNOT-22, a change of one unit preoperatively in all four subscales predicted a statistically significant change of SNOT score at 6 months postoperatively. The preoperative scoring of all the SNOT-22 items was significantly correlated with the postoperative SNOT sum change $(p<0.05)$ within the subscales, except for "Loss of sense of taste/smell", "Post-nasal discharge" and "Thick nasal discharge" (rhinological construct) and "Embarrassed" (psychological construct). Allergic rhinitis, asthma bronchialis and ASA-intolerance were not predictive factors for an improvement in SNOT-22 total score postoperatively $(p>0.05)$. Neither did the VAS scale indicate the postoperative SNOT-22 score improvement.

\section{Duration of symptoms prior to ESS}

Those patients that had the shortest history of sinus disease gained most by SNOT-22 scoring postoperatively (Figure 4). There was a significantly clinical difference (i.e. > 8.9) in postoperative scoring between those that had sinus disease $<12$ months and those that had had a longer disease history (12-60 months and $>60$ months). Preoperatively, the patients with $<12$ months of sinus disease scored $54 \pm 22$, the patients with 12-60 months of disease $53 \pm 20$ and the patients with $>60$ months of disease $52 \pm 22$. Six months postoperatively, the SNOT score dropped to $26 \pm 19,36 \pm 21$ and $31 \pm 20$, respectively. 
Table 4. Probability of patient with CRS with or without NP achieving MCID after ESS based on preoperative SNOT-22 score group.

\begin{tabular}{|ccc|}
$\begin{array}{c}\text { Preoperative } \\
\text { SNOT-22 group }\end{array}$ & $\begin{array}{c}\text { Probability of } \\
\text { achieving MCID in \% }\end{array}$ & $\begin{array}{c}\text { Relative } \\
\text { improvement (\%) }\end{array}$ \\
\hline $0-20$ & 16.7 & 36.3 \\
\hline $21-30$ & 70.0 & -46.1 \\
\hline $31-40$ & 42.9 & -21.7 \\
\hline $41-50$ & 54.5 & -30.8 \\
\hline $51-60$ & 81.3 & -44.6 \\
\hline $61-70$ & 83.3 & -38.0 \\
\hline $71-80$ & 66.7 & -29.0 \\
\hline $81-90$ & 80.0 & -36.3 \\
\hline $91-100$ & 75.0 & -24.3 \\
\hline $101-120$ & 0.0 & - \\
\hline
\end{tabular}

$\mathrm{CRSw} / \mathrm{sNP}=$ chronic rhinosinusitis without $/$ with nasal polyps; $\mathrm{MCID}=$ minimal clinical important difference; ESS = endoscopic sinus sugery, SNOT-22 $=22$ Sinonasal Outcome Test.

The effect of duration of sinus disease could also be detected by the SF-36 scoring (Figure 5 and Table 6). Especially in the physical domains of SF-36, the improvement after surgery diminished the longer the population had the sinonasal problems. VAS scoring also described a bigger improvement after surgery in the group with the shortest rhinosinusitis history ( $<12$ months), (Figure 6).

There was no significant difference in age, gender, nicotine habits or diagnosis between duration groups.

\section{Absenteeism}

Sick-leave due to rhinosinusitis dropped from a modal response of 8-14 days to 1-7 days 12 months after ESS. Preoperatively $20 \%$ of the population reported $1-7$ days of absenteeism, $15 \%$ reported $8-14$ days, and $22 \%$ reported more than 14 days absenteeism compared with $19 \%, 4 \%$ and $11 \%$ postoperatively. Over half of the patients, $57 \%$, reported absenteeism due to sinus problems preoperatively, which decreased to $44 \%$ postoperatively. There was a statistically significant difference of absenteeism 12 months postoperatively compared to preoperatively $(p<0.0001)$.

\section{Discussion}

This prospective multi-centre study showed that ESS significantly improved the HRQOL of patients with CRSW/sNP measured by SNOT-22, SF-36 and VAS at 6 months, with the benefit being maintained at 12 months. The improvement in the mean SNOT22 was both statistically and clinically important, being more than twice the MCID. However, at an individual level, only $64 \%$

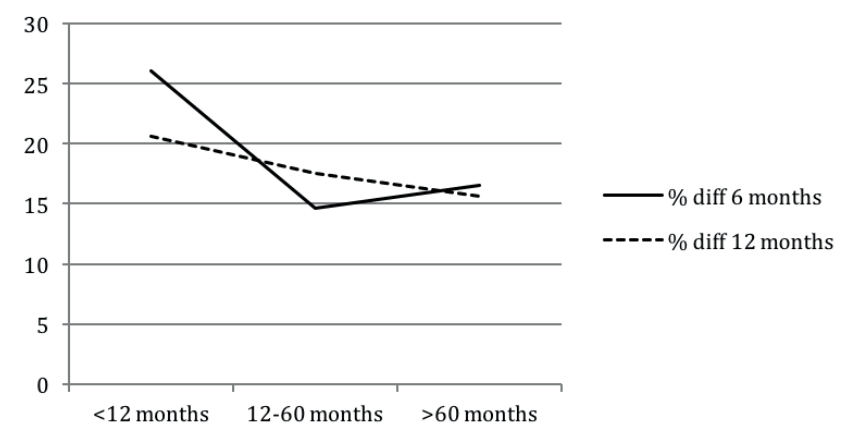

Figure 4. The percentage improvement in SNOT-22 score 6 and 12 months after surgery, according to pre-operative symptom duration. The patients with the shortest disease duration ( $<12$ months) prior to surgery experienced a larger improvement in SNOT-score compared to those with 12-60 and >60 months of sinus disease. SNOT-22 = 22 Sinonasal Outcome Test.

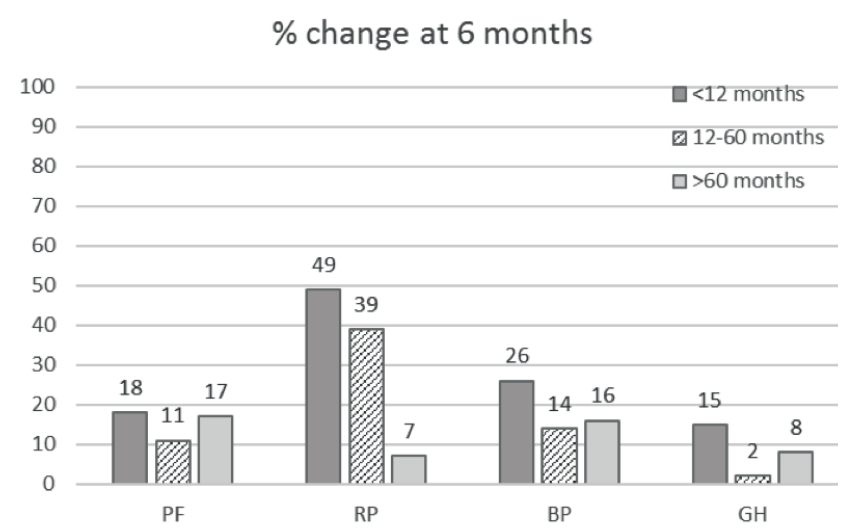

Figure 5. The improvement in the physical dimensions of SF-36 score 6 and 12 months after surgery, according to pre-operative symptom duration. The patients with the shortest sinonasal disease duration ( $<12$ months) prior to surgery experienced a larger score improvement compared to those with 12-60 and $>60$ months of sinus disease. SF-36 $=36$-item short-form questionnaire. $\mathrm{BP}=$ bodily pain; $\mathrm{RP}=$ role physical; $\mathrm{PF}=$ physical functioning; $\mathrm{GH}=$ general health.

of patients achieved the MCID, which is important in terms of preoperative consent. There was no statistically significant difference in overall benefit from surgery between the CRS patients with and without NP, except for in specific items and domains of the questionnaires. This highlights the importance of identifying factors predictive of a successful outcome in order to improve patient selection. Additionally, absenteeism caused by sinonasal symptoms decreased after ESS.

The probability to achieve a clinical measurable change of SNOT-22 at 6 months increased with the preoperative scoring. Patients who scored 61-70 preoperatively were most likely to achieve MCID. For example, patients with a preoperative SNOT22 score higher than 50 points typically have a greater than $81 \%$ chance of obtaining an MCID and receive an estimated 55\% 
Table 5. The results of the linear regression analysis when baseline SNOT22 scores were dichotomized based on a symptom score $\geq 2$.

\begin{tabular}{|c|c|c|c|}
\hline $\begin{array}{l}\text { Symptom Score } \geq 2 \\
\text { SNOT-22 questions }\end{array}$ & $\begin{array}{l}\text { Regression } \\
\text { coefficient }\end{array}$ & $\begin{array}{l}95 \% \mathrm{Cl} \text { Dif- } \\
\text { ference in } \\
\text { SNOT score } \\
6 \text { months } \\
\text { postop }\end{array}$ & p-value \\
\hline 1. Need to blow nose & 17.9 & $5.1-30.7$ & 0.007 \\
\hline 2. Sneezing & 4.1 & $-4.0-12.2$ & 0.315 \\
\hline 3. Runny nose & 8.6 & $-0.1-17.3$ & 0.054 \\
\hline $\begin{array}{l}\text { 4. Blockage/congestion } \\
\text { of nose }\end{array}$ & 15.6 & $1.9-29.2$ & 0.026 \\
\hline $\begin{array}{l}\text { 5. Loss of sense of taste/ } \\
\text { smell }\end{array}$ & 6.9 & $-2.7-16.4$ & 0.158 \\
\hline 6. Cough & 7.4 & $0.1-14.7$ & 0.047 \\
\hline $\begin{array}{l}\text { 7. Post-nasal discharge } \\
\text { (dripping at the back of } \\
\text { your nose) }\end{array}$ & 9.7 & $1.8-17.7$ & 0.017 \\
\hline 8. Thick nasal discharge & 9.7 & $1.8-17.6$ & 0.017 \\
\hline 9. Ear fullness & 9.7 & $2.2-17.1$ & 0.012 \\
\hline 10. Dizziness & 8.0 & $0.6-15.4$ & 0.035 \\
\hline 11. Ear pain & 4.9 & $-3.2-13.1$ & 0.234 \\
\hline 12. Facial pain/pressure & 7.4 & $-0.2-14.9$ & 0.055 \\
\hline $\begin{array}{l}\text { 13. Difficulty falling } \\
\text { asleep }\end{array}$ & 11.4 & $4.3-18.5$ & 0.002 \\
\hline 14. Waking up at night & 10.2 & $2.7-17.7$ & 0.008 \\
\hline $\begin{array}{l}\text { 15. Lack of a good night's } \\
\text { sleep }\end{array}$ & 13.5 & $6.3-20.8$ & $<0.0001$ \\
\hline 16. Waking up tired & 13.7 & $4.9-22.7$ & 0.003 \\
\hline 17. Fatigue & 15.4 & $7.5-23.4$ & $<0.0001$ \\
\hline 18. Reduced productivity & 12.9 & $5.4-20.4$ & 0.001 \\
\hline $\begin{array}{l}\text { 19. Reduced } \\
\text { concentration }\end{array}$ & 11.6 & $4.3-18.8$ & 0.002 \\
\hline $\begin{array}{l}\text { 20. Frustrated/restless/ } \\
\text { irritable }\end{array}$ & 14.2 & $7.2-21.3$ & $<0.0001$ \\
\hline 21. Sad & 11.9 & $4.6-19.2$ & 0.002 \\
\hline 22. Embarrassed & 4.9 & $-2.6-12.3$ & 0.195 \\
\hline
\end{tabular}

SNOT-22 = 22 Sinonasal Outcome Test; $95 \%$ Cl = 95\% Confidence Interval of the Difference. Scoring $\geq 2$ in each item of SNOT-22 were significantly associated with improvement of SNOT-22 total score 6 months after surgery if $\mathrm{p}<0.05$.

improvement in their SNOT-22 score. Conversely, patients who scored below 20 may not provide the desirable clinical outcome, which match the results that Rudmik et al. ${ }^{(34)}$ have described for patients with CRSw/sNP in the US. By providing the patient the chance of achieving a clinical improvement after ESS based on their preoperative SNOT-22 score, these data may help when decision making for surgery. This is further confirmed by a paper

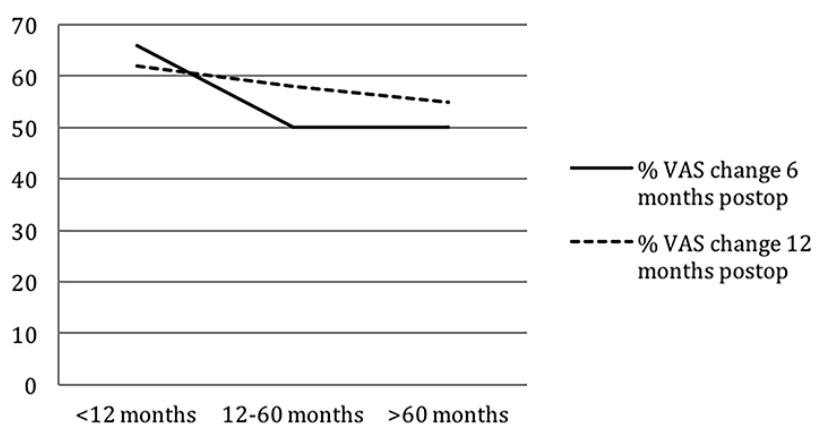

Figure 6. The percentage improvement in VAS score 6 and 12 months after surgery, according to preoperative symptom duration. The improvement is smaller with a sinonasal disease $>12$ months.VAS $=$ visual analogue scale.

published by Rudmik et al. ${ }^{(35)}$ recommending ESS as appropriate treatment for uncomplicated CRSw/sNP when scoring $\geq 20$ in SNOT-22 after a minimum trial of a topical intranasal corticosteroid plus either a short-course of a broad spectrum/culturedirected systemic antibiotic or the use of a prolonged course of systemic low-dose anti-inflammatory antibiotic. In addition, the use of SNOT-22 can also predict the probability of revision surgery. Rudmik et al. ${ }^{(36)}$ has described that failure to achieve an immediate MCID improvement at 3 months and a deterioration of greater than one SNOT-22 MCID from the 3-month to 12-month SNOT-22 score were both associated with an increased risk of revision ESS. The result of ESS have previously been shown not to be affected by addition of corticosteroid treatment postoperatively ${ }^{(37)}$.

Further, scoring more than "mild or slight problem" in 16 of the items of SNOT-22 were predictive for an improvement of the SNOT-22 total score postoperatively. Perhaps surprisingly, we found that "Lack of a good night's sleep" and "Feeling restless/irritable" were the most strongly significant items when predicting changes in postoperative SNOT-22 scores. As sleep disturbance is more common in patients with CRSwNP, it may be that these items are identifying patients with CRSwNP, who have been shown in previous studies to derive greater benefit from ESS. It might also be that sleep deprivation acts as a symptom amplifier, and therefore when sleep quality is improved, it is also associated with greater reduction in other items contained within the SNOT-22. However, "Need to blow nose" and "Blockage/ congestion of nose" are the items with the highest coefficient suggesting them as the strong predicting items when analysing the preoperative rhinological SNOT-22 items.

Scoring of all four constructs in SNOT-22 predicted the postoperative result, showing the importance of using the entire instrument in prepreoperative assessment of the patients with CRS. The patients without NP experienced a greater benefit of surgery in ear/facial symptoms of SNOT-22 compared to the pa- 
Table 6. The improvement in the physical dimensions of SF-36 score 6 and 12 months after surgery, according to preoperative symptom duration.

\begin{tabular}{|c|c|c|c|c|c|c|c|c|c|}
\hline \multicolumn{10}{|l|}{ SF-36 } \\
\hline $\begin{array}{c}\text { Duration } \\
\text { groups }\end{array}$ & & $\begin{array}{l}\text { Preop Mean } \\
\text { (SD) }\end{array}$ & $\begin{array}{l}6 \text { month } \\
\text { Mean (SD) }\end{array}$ & $\begin{array}{l}12 \text { month } \\
\text { Mean (SD) }\end{array}$ & $\begin{array}{c}\text { Mean } \\
\text { change at } \\
\text { preop }\end{array}$ & $\begin{array}{c}\text { Mean } \\
\text { change at } 6 \\
\text { months }\end{array}$ & $\begin{array}{c}\text { Mean } \\
\text { change at } \\
12 \text { months }\end{array}$ & $\begin{array}{l}\% \text { change at } \\
6 \text { months }\end{array}$ & $\begin{array}{c}\% \text { change } \\
\text { at } 12 \\
\text { months }\end{array}$ \\
\hline \multirow[t]{4}{*}{$<12$ months } & PF & $76,8(21,4)$ & $90,3(13,6)$ & $85,8(15,8)$ & 76 & 90 & 40 & 18 & 13 \\
\hline & $\mathrm{RP}$ & $48,9(46,6)$ & $73,4(38,2)$ & $73,2(41,0)$ & 49 & 73 & 73 & 49 & 49 \\
\hline & $\mathrm{BP}$ & $57,1(32,0)$ & $72,4(26,5)$ & $80,4(18,5)$ & 76 & 72 & 80 & 26 & 40 \\
\hline & $\mathrm{GH}$ & $60,0(25,1)$ & $68,6(26,4)$ & $70,7(26,4)$ & 60 & 69 & 71 & 15 & 18 \\
\hline \multirow[t]{4}{*}{$\begin{array}{l}12-60 \\
\text { months }\end{array}$} & PF & $80,0(21,1)$ & $88,6(16,6)$ & $83,1(20,6)$ & 80 & 89 & 15 & 11 & 4 \\
\hline & $\mathrm{RP}$ & $56,5(41,7)$ & $77,7(33,2)$ & $67,6(39,7)$ & 56 & 78 & 68 & 39 & 2 \\
\hline & $\mathrm{BP}$ & $59,4(29,4)$ & $67,0(24,6)$ & $68,1(28,1)$ & 59 & 67 & 68 & 14 & 15 \\
\hline & $\mathrm{GH}$ & $59,5(22,9)$ & $61,2(22,0)$ & $60,0(25,4)$ & 60 & 61 & 60 & 2 & 0 \\
\hline \multirow[t]{4}{*}{$>60$ months } & PF & $82,6(19,0)$ & $88,8(18,1)$ & $86,8(18,6)$ & 83 & 89 & 6 & 17 & 5 \\
\hline & $\mathrm{RP}$ & $70,8(37,6)$ & $76,4(37,4)$ & $73,3(40,1)$ & 71 & 76 & 73 & 7 & 3 \\
\hline & BP & $69,1(29,7)$ & $76,6(28,0)$ & $73,2(26,2)$ & 69 & 77 & 73 & 16 & 6 \\
\hline & $\mathrm{GH}$ & $63,8(23,3)$ & $69,0(22,0)$ & $66,5(26,9)$ & 64 & 69 & 66 & 8 & 3 \\
\hline
\end{tabular}

SF-36 = 36-item short-form questionnaire. $\mathrm{BP}=$ bodily pain; $\mathrm{RP}=$ role physical; $\mathrm{PF}=$ physical functioning; $\mathrm{GH}=$ general health. $\mathrm{SD}=$ standard deviation.

tients with NP, which could be of importance to tell the patients when deciding on which treatment to choose. When asking both patients and health care to list the outcomes from treatments in rhinosinusitis most important to them, the most commonly named symptoms are nasal obstruction, nasal discharge, facial pain and loss of sense of smell followed by overall QOL (38). We have shown that all of these outcomes improved in patients undergoing ESS surgery.

Similar to data reported in the UK ${ }^{(17)}$, we found that a longer duration of sinus disease prior to undergoing sinus surgery seems to diminish the benefits of surgical intervention measured in terms of HRQOL. In the present study, we could also show an effect of the disease duration on the generic HRQOL measured by SF-36. The improvement of HRQOL diminished after living more than one year with sinonasal disease. This reduction of improvement could also be measured with VAS. As medical therapy is usually considered to have failed prior to undertaking sinus surgery, it might be hypothesized that those undergoing surgery at an early stage have more severe and medically recalcitrant disease. They might therefore be expected to receive less benefit from surgery, than those who are deemed not to require surgical intervention at an earlier stage. Exploring the underlying reasons why early surgical intervention is more beneficial than delayed surgery is beyond the scope of this paper. However, it is possible that on-going inflammation, obstruction and infection of the sinuses may lead to irreversible mucosal changes, development of osteitis or accumulation of biofilms, all of which have been found to be associated with difficulty to treat CRS. These specific features need to be examined in relation to symptom duration. When analysing demographic data, there were no significant differences between duration groups at baseline in the present study. Another explanation to the deterioration of improvement after surgery with longer duration of sinus disease, might be that the patient get accustomed to the worse HRQOL and therefore has harder time to "rewind the clock" and remember what normality feels like. A 'response shift' has also been described in patients with long-lasting symptoms; they relatively under-report their symptoms as they cannot remember feeling well, and therefore may appear to report less benefit from surgery than those have surgical intervention at an earlier stage.

We also found that absenteeism caused by sinonasal disease decreased after ESS. There is very little published data regarding either the direct or indirect costs of CRS. Absenteeism is associated with significant costs to individuals, businesses and the wider economy. Previously, the burden of CRS in term of absenteeism had only been examined in the US. This study group was the first to report absenteeism within Europe, with 57\% reporting absence due to CRS symptoms. We found that both the proportion of patients reporting absences reduced and the number of days missed was reduced after ESS. Similarly, Rudmik et al. ${ }^{(21)}$ have found reduced productivity costs associated with receiving ESS for refractory CRS in a pilot study in the USA. In 
that study the absenteeism dropped from 22 to 3 days annually after surgery, and a significant productivity cost was found. However, the population of the American study was much smaller compared to this study (27 compared to 113 patients). Absenteeism will have considerable impact on the overall costs of CRS, and given the relatively modest costs of sinus surgery, gives further support to the benefits of ESS. Additionally, the patients were not asked specifically to exclude time of recovering from surgery, which implies that the decrease in absenteeism could be larger than reported in this study.

This was an observational study reflecting the status of patients with CRSw/sNP as treated in Sweden according to EPOS guidelines and practices. A potential weakness of this study is that the overall case ascertainment rate is not known as participants who declined to participate preoperatively were not recorded and there was progressive loss to follow-up during the study. There was no difference in the preoperative scoring between those patients that chose to respond to the postoperative questionnaires and those who did not. It is of course possible that the data missing in the questionnaires were different from those that were collected and analysed. Despite the concerns described above, it should be emphasized that we have presented data from prospectively enrolled patients, from both university and regional hospitals, diagnosed using uniform criteria from the EPOS document, and that the size of the cohort is considerable.

\section{Conclusion}

This study adds the growing body of evidence that supports the benefits of endoscopic sinus surgery. There is very limited randomized evidence, with 2 trials of a mixed group of patients with CRS, Ragab et al. ${ }^{(8)}$ and Alobid et al. ${ }^{(9)}$, who found that there was no statistical difference between medical and surgical treatment groups (ESS versus systemic steroids, and ESS plus topical steroid versus antibiotics plus high-dose topical steroid). However, as with our cohort, surgery is performed only in patients who have failed a trial of maximum medical therapy, which is often continued over many years, and therefore, the patients randomised to the trials above may not be representative of patients undergoing surgery in the 'real' world. We have demonstrated benefits both in terms of HRQOL and reduced absenteeism. Furthermore, results from our cohort, like the UK prospective audit, suggest greater benefits from early surgery, but uniquely have shown this benefit to be detected using the
SF-36, a global quality of life instrument. Therefore, it is important that ESS remains part of our management pathway for patients with CRS, despite the lack of level 1 evidence. Identifying factors predictive of success with aid of our patients in making decisions regarding surgical management could be one way to improve the further improve $\mathrm{HRQOL}$ of patients. This study points out the importance of using the entire SNOT-22 in pre-preoperative assessment of patients with CRS.

\section{Acknowledgements}

This study was performed with grants from the Swedish ACTA Foundation and Skåne county council's research and development foundation. The authors also wish to thank: Wytske Fokkens, MD, PhD, Department of Oto-Rhino-Laryngology, Amsterdam Medical Centre, Amsterdam, the Netherlands, and Christian von Buchwald, MD PhD, Department of Otolaryngology, Head and Neck Surgery, Rigshospitalet, Copenhagen University Hospital, Copenhagen, Denmark for their guidance in designing this study; and Helene Jacobsson, MSc, R\&D Centre Skåne, Skåne University Hospital, Lund, Sweden, for help with the statistical analysis; as well as the otorhinalaryngologists participating in this study, especially Pernilla Björnberg, MD, Department of Oto-Rhino-Laryngology, Head and Neck Surgery, Skåne University Hospital, Malmö, Sweden; Maria Hillerström, MD, PhD, Department of Oto-Rhino-Laryngology, Uppsala University Hospital, Uppsala, Sweden; Magnus Ivarsson, MD, PhD, Department of Oto-Rhino-Laryngology, Sahlgrenska University Hospital, Gothenburg, Sweden, and Mattias Jangaard, MD, PhD, Department of Oto-Rhino-Laryngology, Karolinska University Hospital, Solna, Sweden.

\section{Authorship contribution}

PSJ contributed to the conception and design of the study, the acquisition, analysis and interpretation of data and manuscript writing. CHcontributed with analysis and interpretation of data and manuscript writing. $\mathrm{BO}$ contributed to the analysis and interpretation of data and the critical revision of the manuscript. MAE contributed to the conception and design of the study, the analysis and interpretation of the data and critical revision of the manuscript. All four authors have read and approved the final version of the manuscript.

\section{Conflict of interest}

No conflict of interest.

\section{References}

1. Fokkens W., Lund V., Mullol J. et al. The European position paper on rhinosinusitis and nasal polyps 2012; Rhinol. Suppl. 23, $1-299$

2. Tomassen P, Newson RB, Hoffmans R, et al. Reliability of EP3OS symptom criteria and nasal endoscopy in the assessment of chronic rhinosinusitis - a GA(2) LEN study. Allergy. 2011; Apr:66(4) 555-61.

3. Lange B, Thilsing T, Baelum J, Kjeldsen A. Quality of life and associated factors in persons with chronic rhinosinusitis in the general population: a prospective question- naire and clinical cross-sectional study. Clin Otolaryngol. 2013; Dec;38(6):474-80.

4. Johansson L, Akerlund A, Holmberg K Melen I, Bende M. Prevalence of nasal polyps in adults: the Skovde population-based study. Ann Otol Rhinol Laryngol 2003;112: 625-9. 
5. Sahlstrand-Johnson P, Ohlsson B, von Buchwald C, Jannert M and Ahlner-Elmqvist M. A multi-centre study on quality of life and absenteeism in patients with CRS referred for endoscopic surgery. Rhinology. 2011; Oct;49(4): 420-8.

6. Deal RT, Kountakis SE. Significance of nasal polyps in chronic rhinosinusitis: symptoms and surgical outcomes. Laryngoscope. 2004 Nov;114(11):1932-5.

7. Hopkins C, Browne JP, Slack R, et al. The national comparative audit of surgery for nasal polyposis and chronic rhinosinusitis. Clin Otolaryngol. 2006; Oct;31 (5): 390-8.

8. Ragab SM, Lund VJ, Scadding G, Saleh HA, Khalifa MA. Impact of chronic therapy on quality of life: a prospective randomized controlled trial. Rhinology. 2010; Sep;48(3): 305-11.

9. Alobid I, Benítez P, Cardelús S, de Borja Callejas F, Lehrer-Coriat E, Pujols L, Picado C, Mullol J. Oral plus nasal corticosteroids improve smell, nasal congestion, and inflammation in sino-nasal polyposis. Laryngoscope. 2014; Jan;124(1): 50-6.

10. Lange B, Tilsing T, Baelum J, Holst R, Kjeldsen A. Diagnosing chronic rhinosinusitis: comparing questionnaire-based and clinical-based diagnosis. Rhinology. 2013; Jun;51(2): 128-36.

11. Bachert C, Zhang N, Holtappels G, et al. Presence of IL-5 protein and IgE antibodies to staphylococcal enterotoxins in nasal polyps is associated with comorbid asthma. Allergy Clin Immunol 2010; 126: 962-968.

12. Dixon AE, Kaminsky DA, Holbrook JT, Wise RA, Shade DM, Irvin CG. Allergic rhinitis and sinusitis in asthma: differential effects on symptoms and pulmonary function. Chest 2006; 130: 429-435.

13. Guerra S, Sherrill DL, Martinez FD, Barbee RA. Rhinitis as an independent risk factor for adult-onset asthma. J Allergy Clin Immunol 2002; 109: 419-425.

14. Jarvis $D$, Newson R, Lotvall J, et al. Asthma in adults and its association with chronic rhinosinusitis: The GA(2) LEN survey in Europe. Allergy 2012; 67: 91-98.

15. Lotvall J, Ekerljung L, Lundback B. Multisymptom asthma is closely related to nasa blockage, rhinorrhea and symptoms of chronic rhinosinusitis- evidence from the West Sweden Asthma Study. Respir Res 2010;11:163.

16. Dietz de Loos DA, Hopkins C, Fokkens WJ. Symptoms in chronic rhinosinusitis with and without nasal polyps. Laryngoscope. 2013; Jan;123(1): 57-63.

17. Hopkins C, Rimmer, Lund V. Does time to surgery impact outcomes of ESS. Rhinology 2015; 53: 10-17.

18. Hopkins C, Andrews P, Holy CE. Does time to endoscopic sinus surgery impact outcomes in chronic rhinosinusitis? Retrospective analysis using the UK clinical practice research data. Rhinology 2015; 53: 18-24.

19. DeConde AS, Mace JC, Bodner T, Hwang PH, Rudmik L, Soler ZM, Smith TL. SNOT-22 quality of life domains differentially predict treatment modality selection in chronic rhinosinusitis. Int Forum Allergy Rhinol. 2014 Dec;4(12):972-9.

20. van Agthoven M, Uyl-de Groot CA, Fokkens WJ, van de Merwe JP, Busschbach JJV. Cost analysis of regular and filgrastim treatment in patients with refractory chronic rhinosinusitis. Rhinology 2002; 40: 69-74.

21. Rudmik L, Smith TL, Mace JC, Schlosser RJ Hwang PH, Soler ZM. Productivity costs decrease after endoscopic sinus surgery for refractory chronic rhinosinusitis. Laryngoscope. 2016 Mar;1 26(3):570-4

22. Piccirillo JF, Merritt MG, Jr., Richards ML. Psychometric and clinimetric validity of the 20-Item Sino-Nasal Outcome Test (SNOT20). Otolaryngol Head Neck Surg. 2002; Jan;126(1): 41-7.

23. Hopkins C, Browne JP, Slack R, et al. The National Comparative Audit of Surgery for Nasal Polyposis and Chronic Rhinosinusitis. Clin Otolaryngol 2006; 31: 390 - 8

24. Hopkins C, Gillett S, Slack R, Lund VJ, Browne JP. Psychometric validity of the 22-item Sinonasal Outcome Test. Clin Otolaryngol. 2009; Oct;34(5): 447-54

25. Lange B, Thilsing T, Al-Kalemji A, Baelum J, Martinussen T, Kjeldsen A. The Sino-Nasal Outcome Test 22 validated for Danish patients. Dan Med Bull 2011; 58:A4235.

26. Lu W, Qi F, Gao ZQ, Feng GD, Yuan XD, Jin XF. [Quality of life survey on patients with chronic rhinosinusitis by using Chinese version of the 22-item sinonasal outcome test (SNOT-22)]. Zhonghua Er Bi Yan Hou Tou Jing Wai Ke Za Zhi. 2008; Jan;43(1): 18-21.24.

27. Baumann I, Blumenstock G, DeMaddalena $\mathrm{H}$, Piccirillo JF, Plinkert PK. [Quality of life in patients with chronic rhinosinusitis: validation of the Sino-Nasal Outcome Test20 German Adapted Version]. HNO. 2007; Jan;55(1): 42-7.

28. Schalek P, Otruba L, Hahn A. Quality of life in patients with chronic rhinosinusitis: a validation of the Czech version of SNOT-22 questionnaire. Eur Arch Otorhinolaryngol. 2010; Mar;267(3): 473-5.

29. Browne et al The Sino-Nasal Outcome Test (SNOT): Can we make it more clinically meaningful? Otolaryngology-Head and Neck Surgery 2007; 136: 736-741.

30. Sullivan M, Karlsson J, Taft C. SF-36: Swedish manual and interpretation guide, 2nd Edition. Gothenburg: Sahlgrenska University Hospital. 2002.

31. Lim M, Lew-Gor S, Darby Y, Brookes N,
Scadding G, Lund VJ. The relationship between subjective assessment instruments in chronic rhinosinusitis. Rhinology. 2007; Jun;45(2): 144-7.

32. Hopkins C, Andrews P, Holy CE. Does time to endoscopic sinus surgery impact outcomes in chronic rhinosinusitis? Retrospective analysis using the UK clinical practice research data. Rhinology 2015; 53-1: 18-24.

33. Fayers P, Machin D. Quality of life: the assessment, analysis, and interpretation of patient-reported outcomes. 2nd ed. Chichester: John Wiley \& Sons Ltd; 2007.

34. Rudmik L, Soler ZM, Mace JC, DeConde AS, Schlosser RJ, Smith TL. Using Preoperative SNOT-22 Score to Inform Patient Decision for Endoscopic Sinus Surgery. Laryngoscope, 2015; 125: 1517-1522.

35. Rudmik L, Soler ZM, Hopkins C, Schlosser RJ, Peters A, White AA, et al. Defining appropriateness criteria for endoscopic sinus surgery during management of uncomplicated adult chronic rhinosinusitis: a RAND/ UCLA appropriateness study. Rhinology 2016; 54: 117-128.

36. Rudmik L, Soler ZM, Hopkins C. Using postoperative SNOT-22 to help predict the probability of revision sinus surgery. Rhinology 2016; Jun;54(2): 111-16.

37. Rawal RB, Deal AM, Ebert CS Jr, Dhandha VH, Mitchell CA, Hang AX, Gore MR, Senior BA, Zanation AM. Post-operative budesonide irrigations for patients with polyposis: a blinded, randomized controlled trial. Rhinology 2015; Sep;53(3): 227-34.

38. Hopkins C, Philpott C, Regan S, Degun A, Papachristou I, Schilder AGM. Identifying the most important outcomes for systematic reviews of interventions for rhinosinusitis in adults: working with Patients, Public and Practitioners. Rhinology 2016; 54: 20-26.

Pernilla Sahlstrand Johnson

Department of Oto-Rhino-Laryngolo-

gy, Head and Neck Surgery

Skåne University Hospital

Jan Waldentröms gata 18

20502 Malmö

Sweden

Tel: +4640332509

E-mail: pernilla.sahlstrand_johnson@ med.lu.se 